\title{
PHOTOGRAMMETRY: METHODS OF SURVEY AND APPLICATIONS ON RESTORATION WORKS
}

\author{
Soraya M. Genin \\ Department of Architecture and Urbanism, ISCTE - University Institute of Lisbon, Lisbon, Lisbon - soraya.genin@iscte-iul.pt
}

Commission VI, WG VI/4

KEY WORDS: Photogrammetry, Restoration Project, Jerónimos monastery in Lisbon, São Miguel - o - Anjo lighthouse in Porto, Cais das Colunas in Lisbon, Alcobaça monastery.

\begin{abstract}
:
This paper presents diverse methods of photogrammetric surveys and applications in restoration works. It compares the methods of survey and highlights their advantages for each specific project. All the methods used showed the great advantage of photogrammetry, compared with the traditional method of survey. There is a great reduction of working hours (field and office). The restitution may be drawn up at any time, with the required degree of rigour, and may be more or less detailed depending on the needs of the Project, case of the dismantling of Cais das Colunas, in Lisbon. The single-image photogrammetry allows the restitution of flat elements, without information on their depth, which is ideal for surveying facades. In the Conservation project of the vaults of Jerónimos monastery church, the traditional stereophotogrammetry had the advantage of stereoscopic vision, allowing a careful observation of the details, anomalies of the construction and a precise diagnostic in situ. Photogrammetry of multiple images is a much faster method for obtaining the 3D model, through a dense cloud of points, which is the most commonly used in recent restoration projects, for heritage documentation and three-dimensional visualisation of the object. This last method was used to survey the church facade of the monastery of Alcobaça. The survey of São Miguel - o - Anjo lighthouse in Porto, and all the other cases, proved that photogrammetric restitution allows a detailed mapping of the construction, necessary for a correct diagnostic of the anomalies to support the Conservation Project.
\end{abstract}

\section{INTRODUCTION}

Firstly, some principles should be considered in Restoration works and Photogrammetry.

The survey of historical buildings should respect the international norms of intervention in the architectural heritage. The photogrammetry is one of the most recommended methods of survey, since it is a non-intrusive method (English Heritage, 2006).

Documenting of historic buildings is the first step for any intervention and planning (Mezzino et al, 2017).

Before starting of the survey, it is necessary to analyse the existing documentation. Often, there are rigorous surveys in the archives, which should be considered in the project. Any new survey should be a complement to the existing one.

The objectives of the survey should be defined according to the objectives of the project and the type of construction to be analysed. For example, the survey requirements are different for the conservation project of a plastered facade or a stone masonry facade. In the first case, the traditional survey may be enough, while in the second case it is undoubtedly a priority to use the photogrammetric method for registering the masonry joints.

Based on the existing data and the objective of the project, the architectural survey must be planned. The goal is to get the geometrical characterisation of the building, but also to document the materials, the construction systems, the chronology of construction, the pathology of the materials and structure. These studies will allow a correct diagnosis that underlies the project.

It is also important to consider that the survey, in the restoration work, can integrate all the phases of the project and the work itself. The project (and the survey) only ends when the work is completed. There are several findings in the work, which require constant surveys, to record, interpret and justify any changes to the project. In many cases, the survey may continue even after the intervention. This is very important, for example for monitoring the behaviour of the structure and the recommended solution.

The article presents different methods of Digital Terrestrial Photogrammetry applied on Conservation projects and works: single-image photogrammetry (or 2D photogrammetry); stereophotogrammetry (two images obtained with parallel axes to each other); Photogrammetry of multiple images (convergence or monoscopic photogrammetry) (Mateus, 2012). To obtain 3D model, the two last methods are possible (Figure $1)$.

The first case presented in this article concerns the Jeronimos monastery church, in Lisbon, where two methods of survey were applied. The facade was surveyed with one single-image photogrammetry. The vaults were surveyed using stereophotogrammetry technique.

The same method was used for the survey of São Miguel - o Anjo lighthouse, in Porto, and the Cais das Colunas, in Lisbon. The first two surveys aimed recording materials and anomalies, to integrate the project of Conservation. The survey of the Cais das Colunas had as objective the partial dismantling, for execution of the work of extension of the meter of Lisbon. 
The photogrammetry of multiple images was the method used to survey the facade of the monastery of Alcobaça, to test software, 3D visualising, restitution of the stone masonry and mapping the pathology of construction.
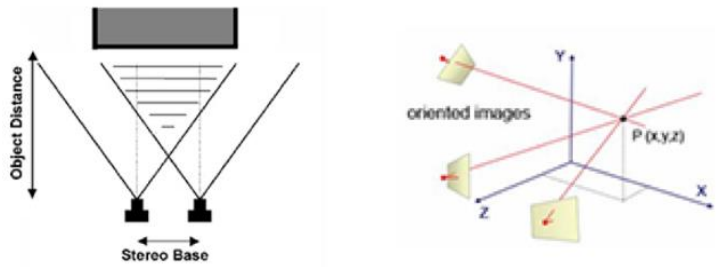

Figure 1. Two methods for obtaining three-dimensional models: stereophotogrammetry with parallel photograps (left) and photogrammetry of multiple images, with convergent photos (right) (Bastian, 2013).

\section{THE JERONIMOS MONASTERY CHURCH}

\subsection{The Conservation Project of the vaults}

The conservation project of the vaults of the church of the Jeronimos monastery was developed between 1999 and 2003, coordinated by the author, at Soraya Genin, Arquitetura e Restauro Lda (SGAR), for the Portuguese Institute of Architectural Heritage (IPPAR).

The project was based on previous research, developed as part of a master thesis on the vaults of the church of the Jerónimos monastery (Genin, 1995). Historical research was completed. The drawings of previous interventions, from 1927-30, found in the archives of the Direção Geral dos Edifícios e Monumentos Nacionais (DGMN), were very well detailed, including general church plans and sections, profile design and details of ribs.

The architectural analysis was carried out based on the archival drawings and the topographic survey. The photogrammetric survey was carried out, but only the field work was completed, the topographic and photographic survey. The restitution was not finished, because it did not serve the proposed goals, of structural analysis, since the results revealed an error, about $0.10 \mathrm{~m}$ in the $\mathrm{z}$ coordinate, in the borders of the photogrammetric model. Several tests were performed to solve the problem. In the end, the software vendor (Digital Video Plotter) was contacted and confirmed to be a standard error.

For the project, the photogrammetric restitution was finished. It was the first phase of the work. The objective was to record the constructive details, for later mapping the materials and anomalies of the construction. For the analysis of the geometry, the profile of the ribs and structural deformations, more topographic surveys were carried out.

\subsection{Survey of the facade}

The survey of the facades was done through single-image photogrammetry, or 2D photogrammetry.

The single-image photogrammetry technique allows the restitution of flat elements without information on their depth. This principle aims to achieve an orthogonal projection of a flat element of the building, obtaining a metric defined twodimensional representation based on an image (image rectification), the elements being manually delineated on it, in which measurements can be taken (Ramirez, 2006).

Figure 2 shows the photograph taken (left image) and the rectified image (right image), where it is possible to verify the distortion of the elements that are not in the plane of the facade. Thus, it is only possible to draw the elements of the rectified plane.

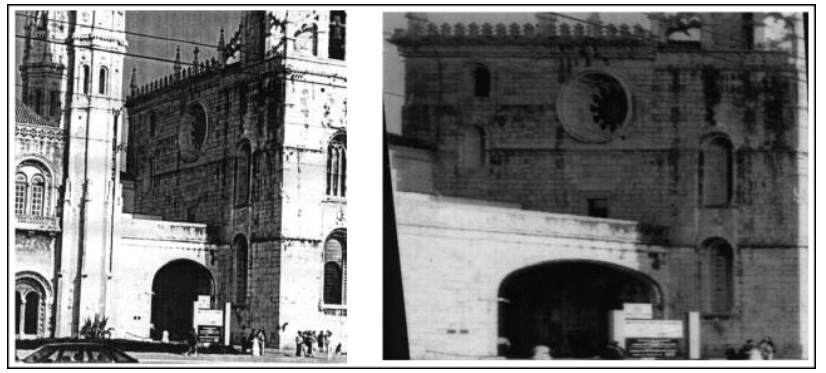

Figura 2. West facade of the church of the monastery of Jerónimos, in Lisbon. Single image photogrammetry (Genin, 1995)

\subsection{Survey of the vaults}

The chosen method of survey was the stereophotogrammetry, a technique based on the use of two photographs of the same object, whose optical axes of the cameras are parallel to each other and the images have the same direction and distance to the object. From a photogrammetric pair it is possible to draw the object (figure 1a).

The photogrammetry with convergent photographs (figure $1 \mathrm{~b}$ ) was tested for the vaults, but stereophotogrammetry was advantageous because it allowed better observation of the vault joints. For the restitution, it is necessary to observe the same object in two photographs, which was not the case with converging photographs, due to the presence of the ribs.

For the photographic survey of the nave's vault, a total of 45 photographs were necessary, 24 in the first three bays and 21 in the choir. Although the choir has a smaller area, the fact that it is closer implies a greater number of photographs. For the topographic survey, five points were recorded for each photogrammetric model (composed of two photographs), which is the number recommended for the photogrammetric pair.

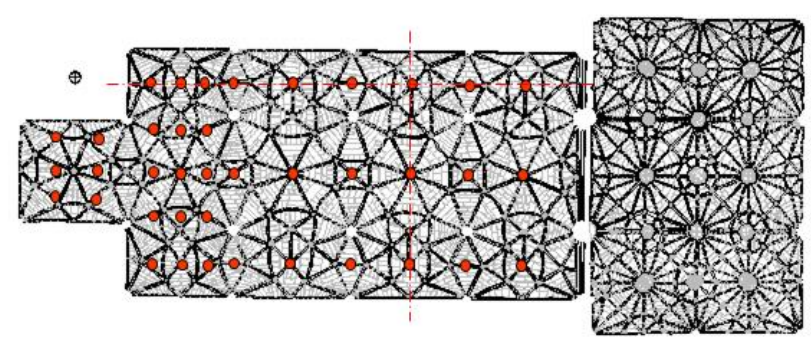

Figure 3. Photogrammetry of the vaults of the church of Jeróniimos monastery in Lisbon. (nave and transept). Location of the photos taken in the nave (Genin, 1995).

The data processing has three steps: i) internal orientation for reproduction of the positioning of the photos at the moment of 
exposure; ii) relative orientation, for reproduction of the positioning of a photo in relation to the other; iii) absolute orientation, for reproduction of the photos in relation to the terrain. In the second phase three-dimensional visualisation is possible. In the last step one can then carry out measurements on a certain scale.

In each photographic image the homologous points are identified. In order to calculate the spatial position of each point, it is necessary to know the parameters of translation and rotation of the camera, obtained at the moment of the photographic image capture, or independently with control points obtained by topography. As each homologous pair is calculated, information about its position and orientation is obtained according to the Cartesian coordinate system (x, y, z), and it is possible to obtain three-dimensional models (Bastian, 2013).
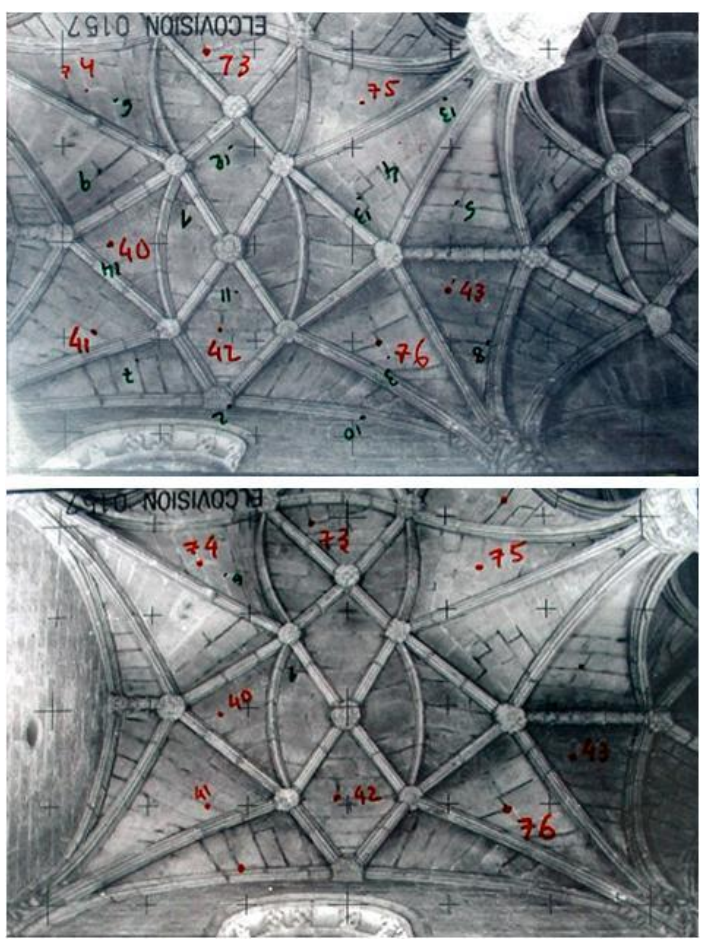

Figure 4. The nave vault of the church of Jerónimos monastery. A photogrammetric pair, with indication of the topographic control points (in red) (Genin, 1995).

The 3D drawings were useful for understanding the shape of the vault and for obtaining plans, sections and elevations.

The restitution based on the stereoscopic view had a great advantage, because it was made by the author, allowing simultaneously to analyse details of the vault, like the stereotomy of the stones, and to verify anomalies, as fissures, detachments and material lacunae.

It was checked that the arrangement of voussoirs varies from one bay to another. The two central bays show a greater rigour of execution: the voussoirs are always arranged concentrically with respect to the central key of each bay. In other bays, the voussoirs are of smaller dimensions and, in the bay next to the transept, their arrangement is very random and disordered.

The stereoscopic observation allowed to analyse several constructive details. It was possible to confirm the double curvature of the voussoirs, their curved section both in the longitudinal direction of the vault, and in the transverse direction. In the nave, octagons and central squares delimit spherical surfaces. These forms are produced by ribs with the same curvature, the surface defined by the voussoirs are not hemispherical, since these are all concave between the ribs. Between the octagons and the walls, the voussoirs follow the curve of the summit, they always remain concave in the transversal direction. The shape is that of a barrel vault.

In addition to the constructive details, structural data were analysed. The dimensions of the voussoirs were verified, confirming that in the octagons they can reach a length of $2.5 \mathrm{~m}$. Plans with level curves were extracted for analysis of deformations. The model was later used for stability analysis applying the finite element method.

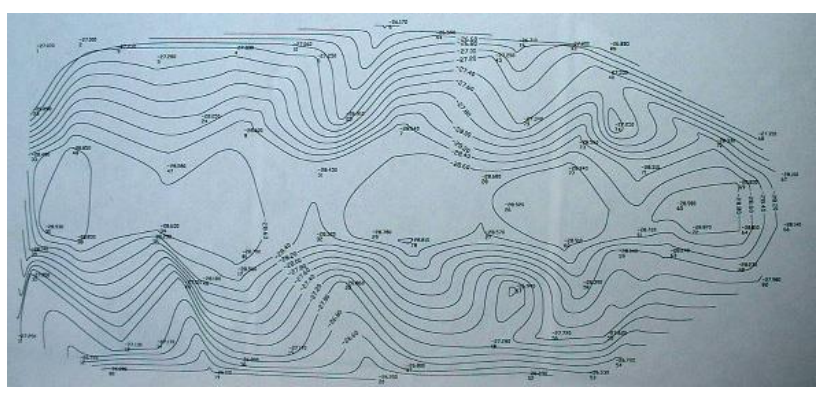

Figura 5. Plan with level curves of the nave vault of the church of Jerónimos monastery (Genin, 1995).

The detailed photogrammetric restitution, with indication of all the joints, permitted the registration of all the materials and anomalies observed. Data were collected about the colour of the stones, the colour of the joints mortars, and also about the decay of the ribs (figure 6).

Several types of limestone were found, the liós used mainly for the ribs, and the Encarnadão and the Amarelo de Negrais, to fill the webs of the vault, more incident in the two central bays. Damp spots were visible on the north side of the nave and the central part of the transept.

The joints were filled with various types of mortar, light-colored lime mortars, and rather dark Portland cement mortar. The light mortars again coincided with the two central bays of the nave vault.

The observation of the ribs confirmed several interventions of the years 1927-30, being clearly identifiable lacunaes and replacements by new stone. Some ribs showed erosion. The lacunaes corresponded to replacements for new stone, as indicated in the archival documents, concerning the intervention.

Finally, the photogrammetry allowed to develop a series of diagnoses from the extrados of the vaults. After the topographic survey of the extradors, the plan was overlapped with that of the intradors. This enabled great precision in the execution of nonintrusive diagnostic. It was used the metal detector and the georadar. This equipment allowed the obtaining of important data, such as the thickness of the voussoirs and the location of the filling masonry of the haunches.

Thanks to the photogrammetry, it was possible to decide previously, with precision, the location for observations of the 
interior of the construction and the ribs through endoscopy and direct analysis.
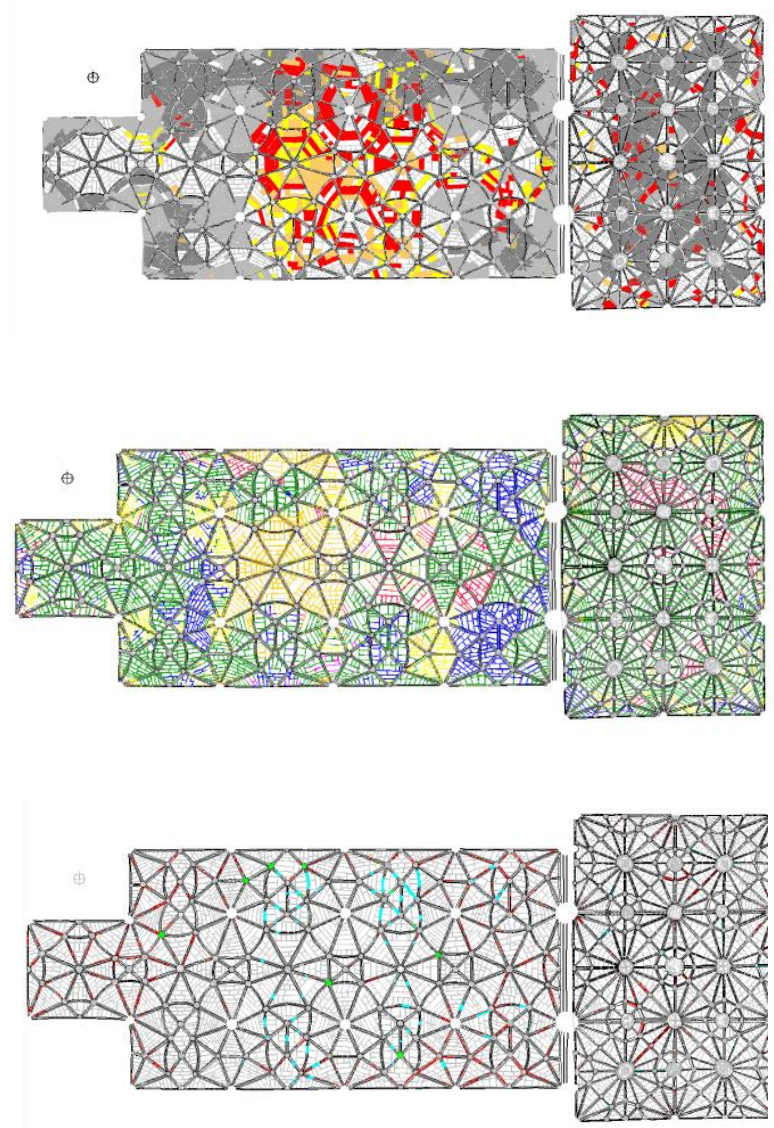

Figure 6. Mapping of the materials and anomalies of the nave vault of Jerónimos monastery: colours of the stones (a) and the joint mortars (b), and pathology of the ribs (c) (Genin, 1999).

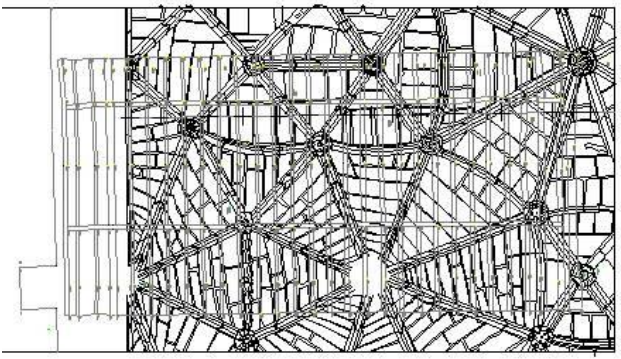

Figure 7. Plan with superposition of the intradors and extradors of the vault of the nave (Genin, 2002a).

All possible information was collected from the extradors, remaining for a later phase, the analysis from the intradors, using scaffolds. This last phase of the project was recently initiated by the Direção Geral do Património Cultural (DGPC), which replaced IGESPAR.

\section{CAIS DAS COLUNAS (QUAYSIDE), IN LISBON}

The expansion of the Lisbon metro, in particular the Santa Apolónia - Cais do Sodré section, involved the dismantling of the Cais das Colunas dock, in 1996-1997. The contract was the responsibility of the company Meliobra, Lda. It was through this company that the author carried out the photogrammetric survey. The work was developed with the collaboration of Instituto Superior Técnico.

The surveying method used was stereo-photogrammetry, with a LEICA Elcovision metric camera and Digital Video Ploter software (DVP), the same equipment and software used for surveying the vaults of the Jerónimos monastery church.

For a survey with photographs of parallel axes, a vehicle of the Firemen, with platform lift was used. At the time no drones were used. The fieldwork was carried out in three days, one day for the photographic survey of the pavement, one day for the photographic survey of the facades, and one day for the topographic survey.

A few days after the field work, the work of dismantling began. The blocks were removed manually, but several fragmented. The fragments were duly identified, and all the pieces were recorded in an inventory form, identifying the stone, the anomalies and their positioning, in the place of origin and in the warehouse, where they were conditioned and restored.

While the work of dismantling was taking place, the cabinet work was carried out, the data processing, the orientation of the photogrammetric models - internal orientation, relative and absolute - as explained for the case of the Jerónimos monastery. Then the photogrammetric restitution was made.

This case proves the enormous advantage of the photogrammetric method in the course of a work, allowing it to start before the survey is completed. As soon as the fieldwork is finished, the restitution is then made in the cabinet, based on the photographs.

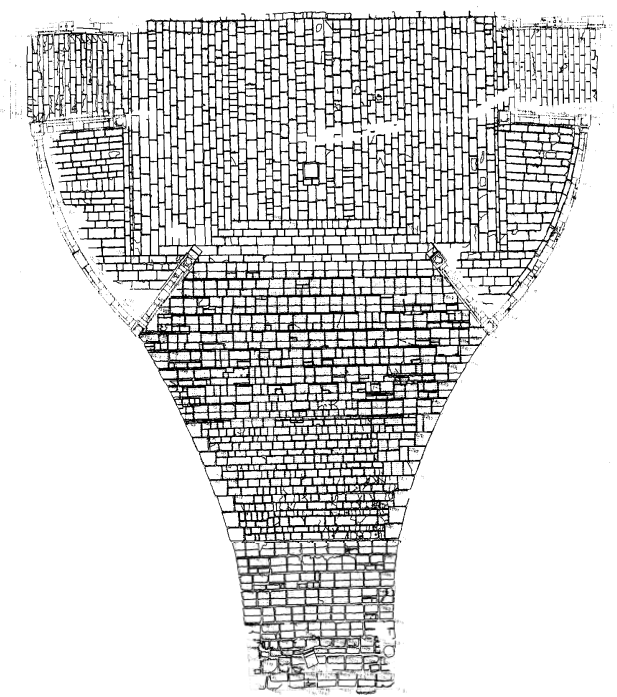

Figure 8. Photogrammetry of the Cais das Colunas, Lisbon. General restitution made during the dismantling (Genin, 1997). 


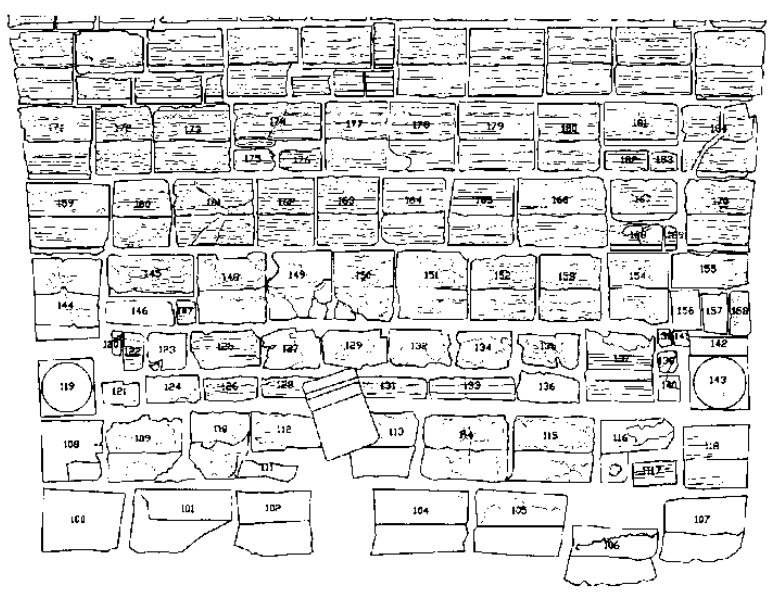

Figure 9. Photogrammetry of the Cais das Colunas, Lisbon Detailed restitution made after the dismantling (Genin, 1997).

It is worth mentioning another advantage of photogrammetry. The cabinet work can take place in several phases. In this case, all the joints were first drawn, in order to number and identify the limits of each block to be removed, a plan used during the work. After the dismentling, the restitution was more detailed, with all the constructive and decorative details of the stoneworks (figure 9).

Photogrammetry allows to perform the fieldwork, and then to draw with a greater or lesser degree of detail, according to the needs of the project or work in progress.

\section{SÃO MIGUEL - O - ANJO LIGHTHOUSE, IN PORTO}

The photogrammetric survey of the São Miguel-Angel lighthouse in Porto, was carried out by ARTOP in 2002, within the scope of a Conservation Project promoted by the World Monuments Fund. The author was responsible for the constructive pathology including the mapping of anomalies, awarded to SGAR.

Thanks to the detailed restitution of the construction, all the materials and anomalies were registered - stones, tiles, metallic elements and mortars. The analysis was carried out in situ, using a lifting platform, for direct observation of the construction anomalies.

In this project, one must highlith the criterion created for the mapping of materials and anomalies. Given the wide variety of typologies of materials and anomalies, various representations were tested, as the graphic legend proposed by the "Raccomandazioni NorMal 1/88 alterazioni machroscopiche del materiali lapidei: lessico" (Lessico Normal 1/88, 1990). The result was not suitable for a good lecture of the plans and interpretation of the materials and decay.

In the past, the mapping of anomalies was preferably only in black colour, because the other colours, in paper, changes over time. Knowing that all information is currently produced in the digital format, this principle is no longer valid.

Thus, a criterion was defined for the registration and mapping of materials and anomalies, based on different hatch patterns and colours.
- Hatch patterns: The forms of alteration have the same hatch pattern for any type of material; the information on mortars and joints are represented with solid colors;

- Significance of the colours: i) Red: superficial and structural alterations (lacunae, plaque, peeling, exfoliation, erosion, holes, fissures and fractures); (ii) Blue: chromatic changes and external elements to the material (black crust, biological colonisation, stain, chromatic alteration, surface deposits); (iii) Green: additional information (other materials: cement mortars), or historical notes (restorations, tiles of the same or extra standard, polychrome, etc); iv) Yellow: given the small size of the tiles and the difficulty of reading the map, in the cases of overlapping anomalies, it was chosen to introduce the yellow, to represent information about the tile (the red represents changes of the glaze, which are superficial).

The result obtained proved the efficacy of the method. The mapping had a great clarity of reading, desirable in this type of documentation, for a correct interpretation of the data.

Measurement criteria were also defined: $\mathrm{m} 2$ for occurrences in stone and plaster; linear meter $(\mathrm{ml})$ for fissures, fractures and joints; units (un) for occurrences in tiles and metal elements, and for holes, metal and wood elements and vegetation.
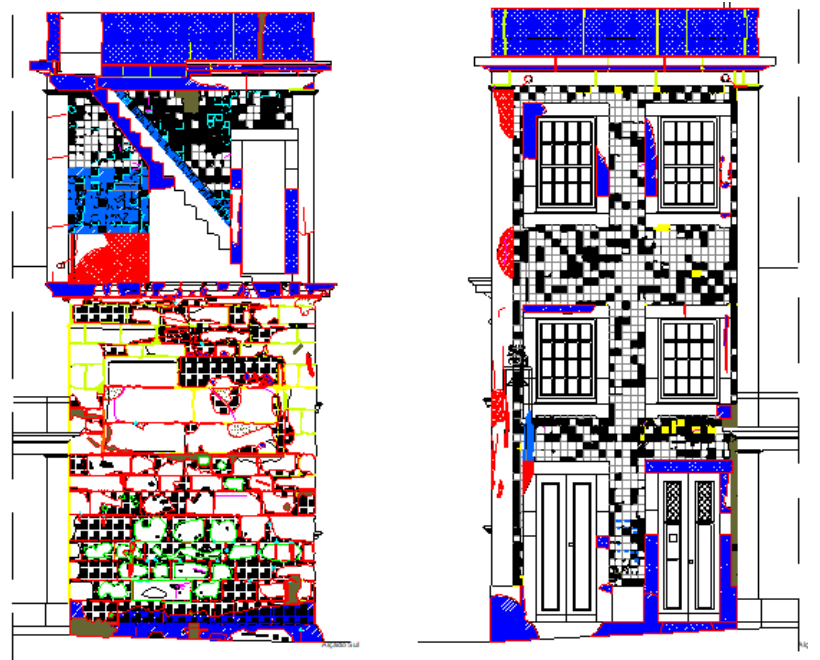

Figure 10. Facades of the São Miguel - o - Anjo lighthouse, in Porto. Mapping of the materials and anomalies, based on the photogrammetric survey (Genin, 2002b).

Based on the survey, the data were extracted, and the information was worked through tables. Several results were obtained, namely:

- Table of quantities of materials and anomalies, which shows the quantities of each anomaly;

- Percentage distribution of forms of decay and alteration. In this graph $100 \%$ of the observed anomaly is considered and its distribution is analysed in each plan or elevation; it is possible to know, for example, where a particular anomaly is more incident;

- Incidence of the forms of decay and alteration by observed area. In this graph we obtain the percentage of each anomaly in the total area observed, in the whole construction and in each 
plan or elevation; it is possible to identify the most incident anomaly in a given elevation.

Based on the interpretation of the mapping and results of the tables, the necessary diagnosis was made to integrate the Restoration project. This was only possible, thanks to the detailed survey.

\begin{tabular}{|c|c|c|c|c|c|c|c|c|c|c|c|c|c|c|}
\hline $\begin{array}{l}\text { Designaga } \\
\text { ân }\end{array}$ & & Total & & $\begin{array}{c}p \\
\substack{p \\
\text { cob }}\end{array}$ & $\begin{array}{c}\mathbf{p} \\
\text { int. }\end{array}$ & $\underset{\text { ext }}{N}$ & $\underset{\text { ext. }}{s}$ & E ext. & wext. & Nint & $\operatorname{sint}$ & Eint & $w_{\text {int }}$ & $\begin{array}{c}\text { Escad } \\
\mathbf{a}\end{array}$ \\
\hline & $\%$ & $\begin{array}{l}\text { Cuannitad } \\
\text { os }\end{array}$ & & ava & $\begin{array}{l}\text { Qua } \\
\text { nt. }\end{array}$ & $\begin{array}{l}\text { oua } \\
\text { nt. }\end{array}$ & $\begin{array}{l}\text { Qua } \\
\mathrm{nt} .\end{array}$ & Quant. & auant. & Quant & Quant & \begin{tabular}{|l|} 
Quant \\
\end{tabular} & Quant & Quant \\
\hline & & 180,03 & $\begin{array}{c}m \\
2\end{array} \mid$ & 每, & 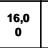 & 6,38 & $\begin{array}{c}35,3 \\
0.3\end{array}$ & 40,75 & 6,45 & 2,45 & 0,24 & 0,97 & 0,25 & 17,15 \\
\hline $\mathrm{A} 1$ & $\%$ & 0,54 & $\mid \begin{array}{c}m \\
2\end{array}$ & & 0,21 & & 0,12 & 0,07 & & & & & & 0.14 \\
\hline A2 & & 4,32 & $\begin{array}{l}m \\
1\end{array}$ & & & 0.64 & 1.51 & 2,17 & & & & & & \\
\hline A3 & & 6,25 & $\begin{array}{l}m \\
1\end{array}$ & & 2,12 & & 1,79 & 1,74 & & & & & & 0.59 \\
\hline A4 & $\%$ & 2,13 & $\frac{m}{2}$ & & & & 0,20 & 1,93 & & & & & & \\
\hline${ }_{A 6}$ & $\frac{12}{12}$ & 22,12 & $\frac{m}{2}$ & & & & 9,61 & 12,51 & & & & & & \\
\hline AB & $\%$ & 0,46 & $\begin{array}{c}\mathrm{m} \\
2\end{array}$ & & & & 0.06 & 0,40 & & & & & & \\
\hline A11 & $\frac{12}{\%}$ & 21,49 & $\begin{array}{c}m \\
{ }_{2}^{2} \\
\end{array}$ & 2,63 & & 5.51 & 4,50 & 3,59 & 5,26 & & & & & \\
\hline A13 & 19 & 33,46 & $\mid \begin{array}{c}m \\
2\end{array}$ & 9,72 & $\begin{array}{c}10,4 \\
2\end{array}$ & 2,17 & 3,45 & 5,81 & 0,37 & 0,19 & 0,21 & 0,97 & 0,16 & \\
\hline
\end{tabular}

Figure 11. Quantitative table of anomalies in each facade, interior and exterior (Genin, 2002b).

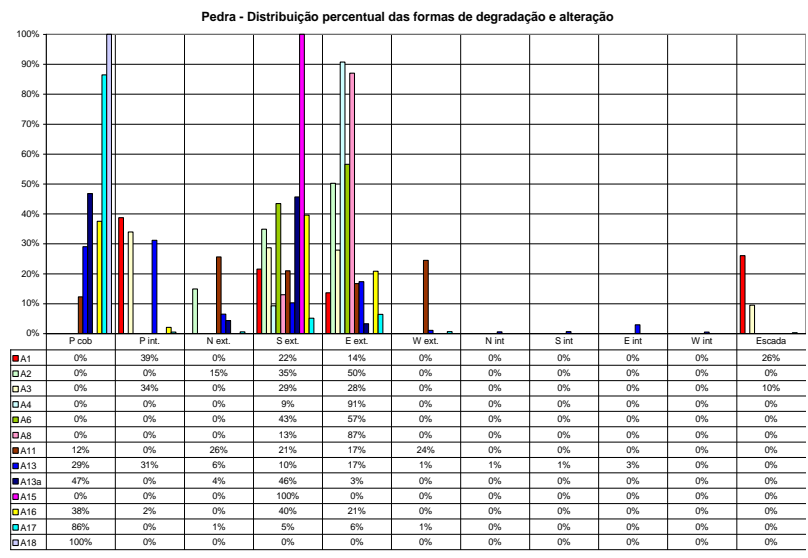

Figure 12. Percentage distribution of forms of decay and alteration (Genin, 2002b).

\section{THE MONASTERY OF ALCOBAÇA}

\subsection{The project}

The photogrammetric survey of the facade of the church of the monastery of Alcobaça, was carried out in 2016, within the scope of a final work of a Master's degree in Architecture of ISCTE-University Institute of Lisbon .The study aimed to test Terrestrial Photogrammetry software and compare results.

The research was also applied in the conservation project of the monastery of Alcobaça, underway in the DGPC, monument manager. This entity made available a CAD survey of the facade, the topographic survey and gave all the necessary logistical support.

The photogrammetric survey was carried out at the Information Sciences and Architecture Technologies Research Center
(ISTAR-IUL), with the collaboration of the Institute of Telecommunications of ISCTE-IUL (IT-IUL) and the Center for Research in Architecture, Urbanism and Design (CIAUD) of the Faculty of Architecture of the University of Lisbon (FAULisboa)

\subsection{The photogrammetric survey of the facade}

In this surveyt it was used the method of multiple-image photogrammetry (Figure 1b), which is based on the principle of triangulation, the intersection of convergent lines in space and the mathematical determination of the position of a point. The determination of this point consists in the orientation of the images to a coordinate system $(\mathrm{x}, \mathrm{y}, \mathrm{z})$, being necessary to know, at the time of capture, the coordinates of the point, at least two images, or preferably three or more images (Bastian, 2013).

Preliminary tests were performed with different drones and cameras. A GoPro Hero, Black Edition camera, with a focal length of $2.77 \mathrm{~mm}$ was chose. The quality of the images was satisfactory, but it was not the most appropriate due to deformation of the fisheye lens

For the photographic survey, a total of fifteen flights were carried out from five pre-defined stations: three stations at a distance of approximately $3,00 \mathrm{~m}$ and $6,00 \mathrm{~m}$ from the facade, and two stations at $12,00 \mathrm{~m}$ apart, for photographs of general framework. From each station, the drone performed three vertical flights, capturing convergent photographs (parallel and oblique to the facade) to obtain images with overlapping homologous points (Figure 13).
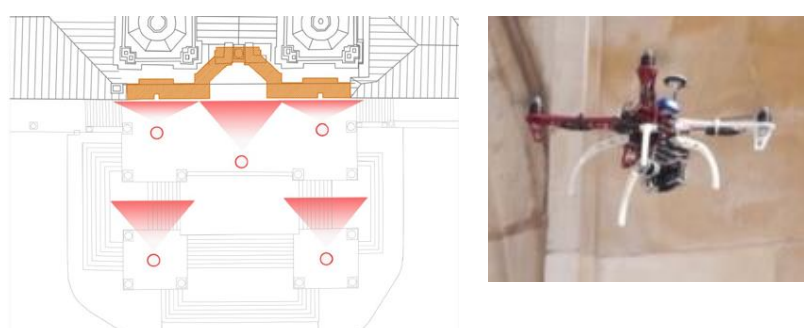

Figure 13. Drone used and location of the five flight stations for photographic survey of the facade of the monastery of Alcobaça (Coelho, Genin, 2016)

A total of 2920 images were captured, with resolution of $3000 x 2250 \mathrm{px}$, and 844 images were selected for production of the model.

A set of eight topographic control points were located in a dispersed form on the façade, easily identifiable (Figure 14). The topographic survey was developed by DGPC

It was tested two photogrammetric software, Visual SFM and Agisoft PhotoScan. The processing of the photographic images is done automatically. First is the rebuilding of scattered sparse clouds of points, followed by the dense reconstruction of clouds of points. The dense reconstruction of the geometry from multiple images is done through the MVS (Multi View Stereo) methodology. In previous cases the processing of photographic images was done manually, both the calibration of the camera and the identification of the homologous points in the various images. 


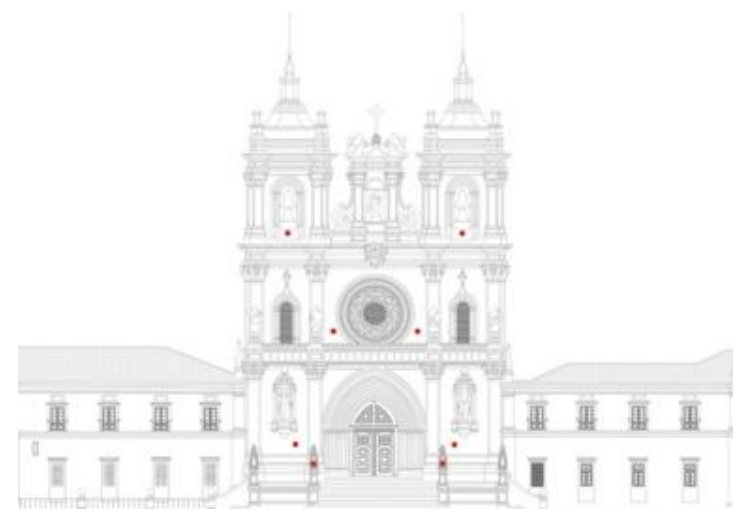

Figure 14. Location of the five control points for the photogrammetric survey of the facade of the monastery of Alcobaça (Coelho, Genin, 2016).

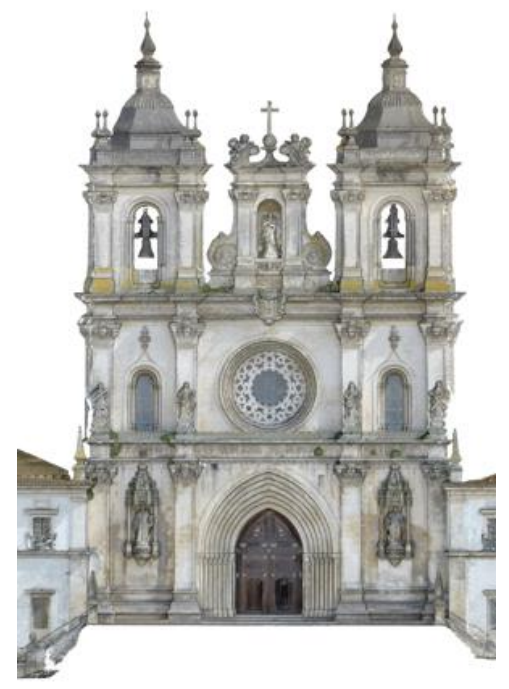

Figure 15. Dense cloud-point reconstruction of the facade of the church of Alcobaça monastery (Coelho, Genin, 2016).

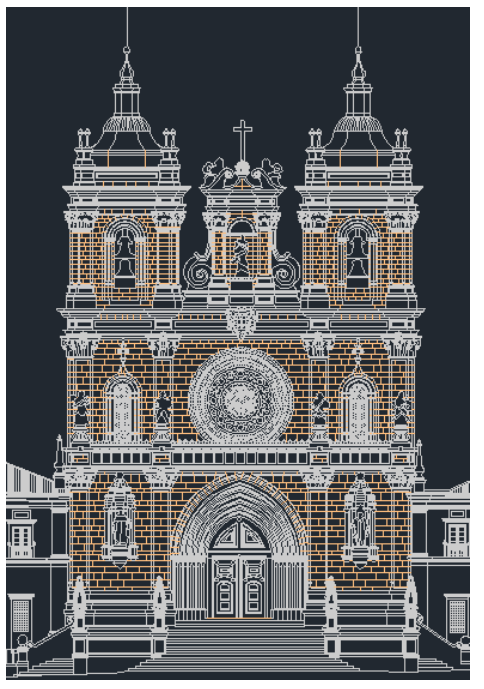

Figure 16. Photogrammetric restitution of the facade of the church of Alcobaça monastery (Coelho, Genin, 2016).
The results confirmed the need for good photographic equipment and camera calibration. The same error was observed in the coordinates $(x, y, z)$, with both software, after the absolute orientation, due to the deformation of the image caused by the photographic lens, with very small focal length.

The dense cloud-point reconstruction of the model produced by Visual FM presented several gaps, while the model produced by Agisoft PhotoScan presented a greater number of points, which allowed a better visualisation of the model and observation of details.

It was used the best definition model for ortho-image and vectorisation production. All visible joints were drawn over the ortho-image. Some joints and anomalies were not identified, mainly due to the high incidence of light on the facade, at the moment of the survey.

Overlapping the image to the elevation provided by the DGPC, a difference in $\mathrm{x}$ and $\mathrm{y}$ was found to be negligible for the intended purpose. Despite the error observed, the photogrammetric survey was helpful for visualising the 3D model and recording of constructive details, necessary to the Conservation Project.

\section{CONCLUSIONS}

In the stereophotogrammetrc survey of the monastery of Jerónimos, the stereoscopic vision was important for the analysis of the constructive details, the stereotomy and the anomalies on the intradors of the vault. Thanks to the photogrammetric survey it was possible to plan a rigorous diagnosis of the interior of the vault, using non-destructive techniques from the extradors. The result of the photogrammetry was insufficient for the analysis of the geometry and deformations of the vaults, due to the error obtained in the coordinate $z$. The geometry was analysed using the topographic survey. However, the 3D model was useful for structural analysis with finite element method.

The photogrammetric survey of the Cais das Colunas (quayside in Lisbon) showed a powerful advantage of the photogrammetry. After the field work - photographic and topographic survey - the restitution was done in two phases. During the work, general drawings were made for the identification and inventory of the stones. After the dismantling the drawings were completed with greater detail.

The photogrammetric survey of the São Miguel - o - Anjo lighthouse was helpful for mapping the materials and the decay. The interpretation of the results through tables allowed the collection of qualitative and quantitative data concerning the materials and anomalies, specify and quantify the works, as required for the Execution Project and work contract.

For the survey of the facade of the monastery of Alcobaça, the photogrammetric software used operates in the SFM (Struture From Motion) system. The result obtained from the dense cloud of points presented some error due to photographic lens distortion, but the method proved to be fast and effective for visualising the 3D model and recording of constructive details, helpful for mapping the materials and anomalies, as required for the Conservation Project.

\section{REFERENCES}

Coelho, A., Genin, S., 2016. Método de levantamento fotogramétrico aplicado ao projeto de conservação da fachada do Mosteiro de Alcobaça [eletronic]. In Congresso Ibero- 
Americano. Património, suas matérias e imatérias, LNEC, Lisbon.

English Heritage, 2006. Understanding Historic Buildings: A Guide to Good Recording Pratice. English Heritage, London.

Genin, S. M., 1995. Étude descriptive de la voûte de l'église du monastère de Santa Maria de Belém à Lisbonne. Master thesis at Katholieke Universiteit Leuven, Leuven (not published).

Genin S. M., 1999. Mosteiro dos Jerónimos, Projecto de conservação e consolidação do tecto da igreja-Análise de materiais e patologias. Report made for IPPAR, Lisbon (not published).

Genin S. M., 2002a. Mosteiro dos Jerónimos, Projecto de consolidação das abóbadas da igreja. Plans made for IPPAR, Lisbon (not published).

Genin, S. M., 2002b. Farol-Capela de São Miguel - o - Anjo. Análise de materiais e patoologias, made for ARTOP (not published).

Mateus, L.M., 2012. Contributos para o Projetcto de Conservação, Restauro e Reabilitação: Uma metodologia baseada na Fotogrametria Digital e no Varrimento Laser 3D Terrestres. [s.n.]. PhD thesis presented at Faculdade de Arquitectura da Universidade Técnica de Lisboa.

Mezzino, D., Barazzetti, L., Santana Quintero, M., El-Habashi, A., 2017. Digital tools for documenting and conserving Bahrain's built heritage for posterity, Int. Arch. Photogramm. Remote Sens. Spatial Inf. Sci., XLII-2/W5, 513-519, https://doi.org/10.5194/isprs-archives-XLII-2-W5-513-2017.

Normal 1/88, 1990. Alterazioni Macroscopiche dei Materiali Lapidei: Lessico, 1-21. Instituto Centrale per il Restauro. 